\section{Information Literacy Instruction with Primo}

\section{Elena S. Azadbakht}

Elena S. Azadbakht, Reference Librarian for Health Sciences and Assistant Professor, University of Southern Mississippi, Hattiesburg, Mississippi.

Correspondence concerning this column should be addressed to Kelly Myer Polacek; email:kmpolacek@gmail.com.

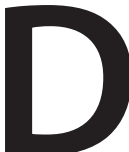

iscovery services are changing the way library users find and access library materials, especially electronic resources. These search tools are also impacting information literacy instruction for users at all skill levels. The University of Southern Mississippi Libraries in Hattiesburg adopted Ex Libris's Primo discovery service during the summer of 2014. ${ }^{1}$ Primo has now been a prominent feature on our website's homepage for almost a full semester and has impacted the way we teach information literacy to our students. As the reference librarian for Health Sciences, I will describe my experience incorporating Primo into our library instruction for both first-year experience and lowerclassmen as well as higher-level courses and how the two approaches differ. I will also describe the biggest challenges our reference services department has encountered when showing our students how to use Primo and how these issues have impacted instruction and our promotion of interlibrary loan. Finally, whenever possible, I will tie in our experiences to the ACRL Information Literacy Competency Standards for Higher Education in an effort to demonstrate how learning and literacy standards can be helpful scaffolds during technological transitions. ${ }^{2}$

Much of the literature on discovery services examines their usability or discusses the implementation of a discovery layer. Several authors, however, address the effects discovery tools have on information literacy and instruction through surveys of librarians and users. Kaufmann, Larsen, and DeSalvo discuss their library's adoption of Primo, how they promoted it, and its impact on information literacy which they assessed via surveys. ${ }^{3}$ Most of their users found Primo intuitive and were able to find adequate results using the tool. Yet the authors observe that the tool didn't "fulfill all information literacy requirements," so they continue teaching users how to search article databases (1.2.c). ${ }^{4}$ In 2011, Buck and Mellinger surveyed instruction librarians whose libraries had acquired the Summon discovery service. More than half of those surveyed reported that Summon had changed their instruction practices, but overall, many had mixed feelings about the tool's impact on information literacy. ${ }^{5}$ Respondents cited large results sets, lack of relevant results, and difficulty limiting searches as their primary criticisms. Some librarians avoided teaching Summon because technical issues made linking to full-text difficult. Respondents reported using Summon in lower-level courses and found it useful for classes in which students were researching a wide variety of topics or for cross-disciplinary research. ${ }^{6}$ Of those librarians who taught Summon, 84 percent did so in undergraduate classes, 51 percent in classes with upperclassmen, and only 
30 percent in graduate-level courses. The nature of the assignment was the biggest factor in the librarians' decision to teach Summon. Of those librarians who never taught the tool, nearly half "noted that Summon did not cover their discipline well." Why teach Summon, wrote one respondent, when a subject-specific database with a controlled vocabulary already existed? ${ }^{7}$

Other librarians have drawn on their own experiences. Fagan reflects on discovery tools and information literacy with the ACRL Information Literacy Competency Standards in mind. She argues that "discovery tools support some traditional information literacy outcomes, while failing to support others." By combining different collections and vocabularies, discovery tools do not help students "recognize that knowledge can be organized into disciplines that influence the way information is accessed" (1.2.b.) or understand the difference between primary and secondary sources (1.2.e.). Students are also less likely to develop strategies for revising their searches or reevaluating their information needs if they routinely use a discovery tool. Fagan implores librarians to "make up for these tools' inadequacies and capitalize on new opportunities." Fawley and Krysak establish a set of best practices that librarians can use to develop instruction sessions that incorporate the use of a discovery tool. ${ }^{10}$ They recommend that librarians focus on helping students develop search terms, use limiters effectively (2.2.b.), emphasize interlibrary loan (1.3.a.), and devote more time to teaching critical thinking skills. They also encourage using discovery tools as "a scaffold for subject-specific databases."11 I found myself employing many of these same strategies prior to discovering Fawley and Krysak's work.

At the University of Southern Mississippi's main library, Cook Library, each reference librarian is responsible for providing instruction for the departments and classes within his or her assigned college within the university. Much of the instruction we do is in the form of one-shot workshops. Reference librarians are allowed a good amount of flexibility in terms of what topics we cover and how we cover them in order to accommodate the needs of a particular course or assignment. I vary how I teach Primo depending on the course, the nature of the project or assignment, and the skill level of the students involved.

Primo is a web-scale discovery service provided by Ex Libris. A single search in Primo will retrieve results from our catalog, digital collections, institutional repository, most of our subscription databases, and resources from the Primo Central index-a large collection of scholarly electronic resources from a mix of publishers, aggregators, and openaccess repositories. Results from all of these collections are combined into a single, relevancy-ranked results list.

Although initially I worried Primo's presence would mean that users missed out on some of the great resources available to them in our specialty databases, the benefits of Primo's results to our "lowest common denominator" students (i.e., first years and new library users) outweighed these concerns. Primo supplies a single intuitive interface and allows users to search across many collections and platforms. In this way, Primo is more akin to Google and Google Scholar. Since searching Primo does not require learning each individual database's distinct interface and unique features, students lacking research experience are more likely to find reliable, high-quality resources through the library.

However, Primo does have its unique features and quirks that must be taken into consideration when designing quality information literacy instruction. Primo's search features differ slightly from those of several major article databases. At Cook Library, we get most of our highly-used databases, including Academic Search Premier, PsycINFO, and MEDLINE, through EBSCO. As a result, our students are most familiar with the EBSCOhost interface. Unlike EBSCOhost, the Boolean operators AND, OR, and NOT must be in all uppercase letters for Primo to interpret the query correctly; thus students need explicit instruction on using appropriate commands for information retrieval (2.2.d.). Users can limit Primo results by "scope," which includes broad categories like articles and items within the library catalog, as well as by library collection (e.g., special collections, institutional repository, etc.) and resource type (e.g., articles, dissertations, books, e-books, etc.). Libraries do have some control over scope names and the order in which limiters appear on their Primo search pages. Nevertheless, distinguishing between these options can be confusing to those new to research or to those used to searching a traditional article database. Primo also offers up related Library of Congress subject headings as limiters. While this limiter is helpful in many situations, the more subject-specific thesauri and indexes available in proprietary databases are often more useful to users unfamiliar with a field's jargon (2.2.c.).

Primo's "Expand my results" option is another potentially confusing feature. Checking this box widens a search to include all materials indexed by Primo whether or not a patron's home library owns these materials. Libraries can choose to make this type of search the default, but since we noticed that users were more likely to get discouraged and give up when they encountered mostly hard-to-obtain sources, we opted to have our Primo widget search just those items we have fulltext in our print and electronic collections.

There are also challenges to accessing various items found through Primo. We use Millennium rather than Ex Libris's catalog product, so real-time connection to holdings information is not seamless in Primo. The system's workaround for this is a link labeled "Check holdings at ...., followed by the item's location and call number. This link opens the Classic Catalog record for the title in a new window, where users can check the item's availability. Furthermore, Primo taxes our link resolver, since many of our subscription items are accessible only via the proprietary databases or electronic journal platforms that house them. When our link resolver is not functioning properly, it appears as if none of our databases are working. A similar issue occurs if users check the "Expand my results" box and come across items we do not have. The "details" section of these items list the source (e.g., 
a citation-only database indexed by Primo Central) but does not always work with our LinkSource tool, Find It! In article databases, Find It! provides a link to interlibrary loan/ILLIAD for titles we do not have full-text so that users can request them. In Primo, the interlibrary loan option is not apparent in those situations where only the citation is available through one of our subscription databases. This may not be a problem for advanced researchers familiar with interlibrary loan but is a potential barrier for novice researchers. They may assume the item in question is inaccessible. I use example searches to address these challenges head-on in information literacy instruction sessions.

There are Primo features and functions that I bring to the attention of students in almost all of the one-shot instruction sessions I teach, whether they are introductory or upper-level. For example, instead of showing students how to search for books and other media in the Classic Catalog, I now do so using Primo. Since we feature the Primo search box front-and-center on our website's homepage, it is what students at all levels will try first when searching for books on their own. Also, if they decide to refine or alter their initial search to include other material types like articles or open access resources, doing so with Primo is much easier-they will not have to navigate to a completely different site and redo their search. There are, of course, situations where our catalog is the better option. Locating special media types like maps or older (not yet digitized) dissertations, for instance, is easier with the Classic Catalog. For the most part though, Primo suffices.

I also encourage students at all levels to use Primo when they need an exact title match. For example, they might use Primo to find a specific article their instructor has asked them to read. It is easier to search for the title of the article in Primo than to search for the journal in our catalog and navigate to the database it is in or the physical shelf it is on. Students might use Primo to see if we have a copy of a book they want to read, like Great Expectations. In situations where the student has very little information on the item they are seeking other than its title or author, using Primo saves time.

Although my primary responsibility is to our allied health and nursing programs, I am often called upon to provide instruction for sections of various introductory courses like English 102 (composition), University 101 (orientation to higher education and Southern Miss), and Commutation Studies 201 (rhetoric). I also work with several groups of students in introductory health courses like Introduction to Health Education, wherein assignments typically are less involved and require less in-depth resources than their upper-level counterparts. For most major assignments in these classes, students are free to write or present on any number of topics so long as they use scholarly resources to support their arguments. Consequently, library instruction sessions need to be general enough to apply to a wide range of subjects yet be intuitive enough for novice researchers to follow. Before Primo, I showed these classes how to search for articles using Academic Search Premier, as it contains scholarly resources on a wide range of topics and is user friendly. Primo works even better for this type of demonstration and includes a fuller variety of resource types, like books and DVDs. I demonstrate how to use Primo to locate different kinds of materials on several different topics. According to ACRL Standard One, an information literate student "defines and articulates" the need for information. Knowing the "value and differences of potential resources in a variety of formats" is one key outcome of this trait, which Primo can help develop (1.2.c.). I still help these students understand the difference between peer-reviewed and non-peer-reviewed sources and learn how to identify trustworthy sources of information-I simply do more of it using the results of Primo searches.

I also still stress the importance of choosing good keywords. An information literate individual must be able to identify "key concepts and terms that describe the information need," (1.1.e.). As Fawley and Krysak found, teaching students how to come up with and use keywords effectively is still an important aspect of information literacy in the era of "Google-like" discovery tools. ${ }^{12}$ Although Primo's algorithm is powerful, using good search terms still yields more relevant results. I spend a good bit of time on this in my instruction sessions. I have students think about the keywords that would work best for their topics and sometimes use these as the basis for in-class example searches. I show students how combining sets of keywords in various ways can sometimes lead to different results. This emphasis on keywords helps develop search skills they can use after they graduate-when they may not have access to library resources and will need to be able to search Google effectively. Primo is much more Google-like than most articles databases and facilitates this kind of skill building. They are learning how to transform key concepts into usable search terms.

Primo can serve as a gateway to subject-specific resources like PsycINFO or Westlaw. Helping students determine when to switch to individual databases to find more pertinent information is another important aspect of teaching with Primo; it helps students "recognize that knowledge can be organized into disciplines that influence the way information is accessed" (1.2.b.). After identifying those terms that recur within a Primo search on a topic, I navigate to an appropriate subject database. I use examples that illustrate how tweaking or using different combinations of keywords can produce better results in the jargon-heavy databases. By the time we get to the demonstration of these databases, the students will have seen how Boolean operators and limiters work in Primo and should be less intimidated by the databases' search interfaces (1.1.c.).

As discussed above, I also emphasize interlibrary loan in these courses. If a search in Primo is not proving successful, I explain how clicking on the "Expand my results" box can widen the search. Although we may not have full-text access to these other books, articles, and documents, it is an opportunity to explain that the library can still connect them to these resources. For many students, this is the first time they have heard of interlibrary loan. Since so much is available 


\section{INFORMATION LITERACY AND INSTRUCTION}

online through a quick Google search or available in full-text through a Primo search, incoming students might be inclined to pass over those potentially great resources that are harder to come by. Walking them through the request process using information found through Primo or WorldCat emphasizes how quick and simple (though less immediate) getting ahold of these resources can be. This helps them learn how to "[determine] the availability of needed information and makes decisions on broadening the information seeking process beyond local resources," (1.3.a.).

My instruction for upper-level courses, particularly those at the graduate level, remains focused on subject-specific databases. I do, however, encourage the use of Primo for finding certain nonarticle sources in lieu of the library catalog, as I described above. Primo has been a useful tool for those students looking for example theses or dissertations related to their own area of research and for those looking for information contained in datasets or other special formats. In a social work course, students needed to locate national, state, or local data and information related to the client populations and treatment options they were researching. Since it casts a wider net, Primo turned up relevant resources that were not readily available in traditional article databases. I also advise upper-level students that Primo is a good way to browse for interdisciplinary information on their topics. They may come across interesting ideas and discussions from sources they might not have considered. Searching Primo can also serve as a last-ditch attempt at finding information if the recommended subject-specific databases are not turning up much on their topic, especially if they are doing interdisciplinary research. I have helped students successfully track down older references through Primo.

When I do spend time on Primo in these upper-level courses, I typically focus on Primo's advanced search. It differs from those of most proprietary databases but shares some similarities with Google Scholar's advanced search form. Both systems share a similar aesthetic, let the user limit their search to an exact phrase, search for specific authors, and restrict their results to titles containing their keywords. I demonstrate a complex search using Primo's advanced search options before moving on to the subject-specific databases most relevant to the course. Most of these students will eventually take on professional roles where they will no longer have access to academic library resources yet they will still need to find scholarly information effectively. Becoming comfortable searching Primo will get them to academic resources they can use now while simultaneously giving them skills that will benefit them long term.

Despite my initial concerns that Primo might change students' search habits for the worse, I have found ways to use the discovery tool to my advantage in information literacy instruction sessions. I have even managed to take some of the challenges of using Primo and use them to highlight the need for information literacy skills and library resources such as interlibrary loan. I will likely need to continue to adapt my teaching as Primo itself evolves in response to user needs. There are many advantages to Primo, particularly for those new to library resources and research, which makes adoption of the tool worthwhile. Since discovery systems are not perfect, however, flexible information literacy instruction is still necessary for student success.

\section{References}

1. Ex Libris, Primo, www.exlibrisgroup.com/category/PrimoOverview.

2. "Information Literacy Competency Standards for Higher Education," Association of College and Research Libraries, 2000, www.ala .org/acrl/sites/ala.org.acrl/files/content/standards/standards.pdf.

3. Karen Kaufmann, Jeanne Larsen and Patricia DeSalvo, "Discovering the Discovery Tool: The Introduction and Impact on Research and Instruction at Seminole State College of Florida," College $E$ Undergraduate Libraries 19, no. 2-4 (2012): 278-96.

4. Ibid.

5. Stefanie Buck and Margaret Mellinger, "The Impact of Serial Solutions' Summon TM on Information Literacy Instruction: Librarian Perceptions," Internet Reference Services Quarterly 16, no. 4 (2011): 159-81.

6. Ibid.

7. Ibid.

8. Jody Condit Fagan, "Discovery Tools and Information Literacy," Journal of Web Librarianship 5, no. 3 (2011): 171-78.

9. Ibid.

10. Nancy Fawley and Nikki Krysak, "Information Literacy Opportunities within the Discovery Tool Environment," College \& Undergraduate Libraries 19, no. 2-4 (2012): 207-14.

11. Ibid.

12. Ibid. 